\title{
Acknowledgement to Editors and Scientific Referees 2020
}

\begin{abstract}
A scientific journal's greatest responsibility is to ensure that all contributions accepted for publications are rigorously but fairly reviewed. The Editor-in-Chief and Archives of Pediatric Neurosurgery gratefully acknowledge the qualified and regular collaboration of renowned medical doctors and scientists who kindly devoted their time to constructively review the submitted articles. Their expertise and invaluable assistance contributed to maintain a high scientific standard for APN. We are thus indebted to the Editorial Board members and the following experts who reviewed papers and completed the peerreviewing process within 2020 .
\end{abstract}

Alexandre Casagrande Canheu

Alexandre Varella Giannetti

Aline Saré de Melo

Angelo Raimundo da Silva Neto

Artur Henrique Galvão Bruno da Cunha

Carlos Umberto Pereira

Eduardo Jucá

Jose Roberto Tude Melo

Leopoldo Mandic Furtado

Luciano Lopes Furlanetti

Marcelo Volpon Santos
Marcos Devanir Silva da Costa

Matheus Ballestero

Patricia Alessandra Dastoli

Paulo Ronaldo Jubé Ribeiro

Ricardo Gepp

Ricardo Santos de Oliveira

Roberto Alexandre Dezena

Sergio Cavalheiro

Simone Rogerio

Tatiana Protzenko 